\title{
Overexpression of brachyury contributes to tumor metastasis by inducing epithelial-mesenchymal transition in hepatocellular carcinoma
}

\author{
Rui $\mathrm{Du}^{1}$, Shanshan $\mathrm{Wu}^{1}$, Xiaoning $\mathrm{Lv}^{2}$, Henghu Fang ${ }^{1}$, Sudong $\mathrm{Wu}^{1}$ and Jingbo Kang ${ }^{1 *}$
}

\begin{abstract}
Aims: Brachyury overexpression has been reported in various human malignant neoplasms, but its expression and function in hepatocellular carcinoma progression and metastasis remains unknown. The present study aimed to evaluate the critical role of Brachyury in HCC metastasis.

Methods: The expression of Brachyury in human HCC (SMMC7721, HepG2, FHCC98, and Hep3B) and control cell lines was analyzed using quantitative reverse-transcriptase polymerase chain reaction and immunoflourence methods. Cancerous tissues collected from patients with HCC $(n=112)$ were analyzed using immunohistochemical method; a microarray analysis of HCC tissues was performed to explore the clinicopathological variables of HCC. The migratory and invasive capacities of Brachyury-SMMC7721 and Brachyury-HepG2 transfected cells were evaluated using in vitro scratch wound healing and Matrigel invasion assays, respectively. Further, six-week-old male BALB/c nude mice $(n=10)$ model was used in vivo assay.
\end{abstract}

Results: Elevated expression of Brachyury was detected in HCCs (62.5\%) compared with that in adjacent nontumorous tissues. Clinicopathological analysis revealed a close correlation of Brachyury expression with distant metastasis and poor prognosis of HCC. Overexpression of Brachyury promoted epithelial-mesenchymal transition (EMT) and metastasis of HCC cells in vitro and in vivo. Brachyury overexpression enhanced Akt activation by inhibiting phosphatase and tensin homolog (PTEN), which led to subsequent stabilization of Snail, a critical EMT mediator.

Conclusion: The study findings suggest that elevated Brachyury facilitates HCC metastasis by promoting EMT via PTEN/Akt/Snail-dependent pathway. Brachyury plays a pivotal role in HCC metastasis and may serve as a novel prognostic biomarker and therapeutic target.

Keywords: Hepatocellular carcinoma, Brachyury, Cancer metastasis, Epithelial-Mesenchymal Transition, PTEN/Akt/Snail-Dependent Pathway

\section{Introduction}

Hepatocellular carcinoma $(\mathrm{HCC})$ is ranked as the fifth most frequent cancer and third most frequent cause of cancer deaths in the world [1]. In spite of improvements in surveillance and clinical therapeutic strategy, long-term disease-free survival (DFS) of patients with HCC remains unsatisfactory due to tumor recurrence and metastasis of the primary tumor [2,3]. Metastasis is not only a complex process but also the major cause of cancer-

\footnotetext{
* Correspondence: Kjbnet@126.com

Equal contributors

'Department of Radiation Oncology and Integrative Oncology, Navy General Hospital, 6\# Fu Cheng Road, Beijing 100037, People s Republic of China

Full list of author information is available at the end of the article
}

related deaths [4]. Epithelial-mesenchymal transition (EMT) describes a series of events during which cells lose epithelial characteristics such as cell-layer organization and apical-basolateral polarization and acquire properties of mesenchymal or fibroblastoid cells including motility [5]. EMT is known to be a central mechanism responsible for invasiveness and metastasis of various cancers [6,7]. Increasing evidences suggest that activation of Rho-family of small GTPases, cytoskeletal rearrangement, and nuclear translocation of several transcription factors such as Snail and Twist play important roles in the processes of cancer cell metastasis through modulation of cancer cells EMT

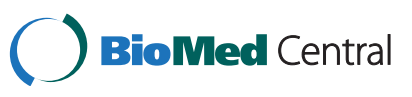


[8-10]. However, the underlying mechanisms of cancerrelated EMT are not fully elucidated.

The T-box transcription factor, Brachyury, is vital for the formation and differentiation of posterior mesoderm and axial development in vertebrates [11]. Interestingly, Brachyury is located at $6 \mathrm{q} 27$, which is a frequently amplified region in HCC [12]. The function of Brachyury has extensively been characterized in mice and zebrafish $[13,14]$. An earlier study on Brachyury-mutant mice model without $\mathrm{T}$ protein reported in utero death with abnormal notochord, absent somites, and reduced allantois [15]. In zebrafish, the no-tail mutation $(\mathrm{Ntl})$ is the homolog of Brachyury; the Ntl embryos die soon after hatching with lack notochords and tails, and they possess abnormal trunk somites. The $\mathrm{T}$ gene encodes a transcription factor that binds to a specific DNA element via its N-terminal region [14]. In humans, T-box transcription factors are major players in the regulation of the progenitors and their differentiated descendants $[11,16]$. Brachyury is expressed in the progenitor population throughout somitogenesis, suggesting that it plays an essential role in keeping the progenitor population viable [17]. Meanwhile, Brachyury is also dysregulated in various human malignant neoplasms $[18,19]$. Recently, Brachyury was demonstrated to induce EMT in human epithelial cells through induction Snail, Slug, and downstream signal [20]. An earlier study on human lung carcinoma cells (in vitro and in vivo) has demonstrated that overexpressed Brachyury divides at slower rates than those with lowexpressed Brachyury, a phenomenon associated with marked downregulation of cyclin D1, phosphorylated Rb, and CDKN1A (p21) [21]. Another study on oral squamous cell carcinoma cells demonstrated that the expression of Brachyury was correlated with EMT and was significantly associated with lymph node and distant metastasis [22]. The above evidences indicate that Brachyury may be a critical regulator of carcinogenesis and tumor metastases in different cancers. Until now, no studies have reported its roles in HCC. Hence, the present study aimed to evaluate the Brachyury expression in patients with HCC and in HCC cell lines and its clinicopathological significance in HCC.

\section{Materials and methods \\ Cell culture}

Human simian virus 40-transformed immortal liver epithelial cells (QZG) and HCC cell lines SMMC7721, HepG2, FHCC98, and Hep3B were purchased (Bei Na Biotechnology Research Institute, Beijing, China) and preserved [23]. Cells were maintained at $37 \mathrm{C}$ with $5 \%$ carbon dioxide in Dulbeccos Modified Eagles Medium (DMEM) (Gibco Life Technologies, Grand Island, USA), supplemented with 50 units $/ \mathrm{ml}$ penicillin, $50 \mathrm{mg} / \mathrm{ml}$ streptomycin, and 10\% fetal calf serum (Gibco Life Technologies, Burlington, Canada).

\section{Patients and tissue samples}

Patients $(n=40$; aged between 32 and 79 years with a mean age of 50.1215 .02 years), who underwent hepatectomy for HCC between January 2006 and August 2008 in the Department of General Surgery, Xijing Hospital (Xi an, China), were included in the Brachyury and vimentin correlation analysis. Tissue chips for HCC primary tumors were purchased from National Engineering Center for Biochip Design, Shanghai Biochip Co. Ltd., Shanghai, China. The tissue chips $(n=72)$ were used in the clinicopathological correlation and survival analysis. None of these patients received preoperative chemotherapy or radiotherapy. All tumor samples were derived from dissected tumor tissues and were composed of more than $90 \%$ of tumor cells without necrosis. The surgical specimens (both tumor and adjacent nontumorous tissues) were processed immediately after the operation and snapfrozen in liquid nitrogen for protein, DNA, and ribonucleic acid (RNA) extraction. All patients with HCC gave written informed consent on the use of clinical specimens for medical research. Studies using human tissues were reviewed and approved by the Committees for Ethical Review of research involving human subjects of Fourth Military Medical University, Xi an, China.

Immunohistochemistry (IHC) and Immunofluorescence (IF) For IF analysis, SMMC7721 and HepG2 cells were cultured on sterile glass coverslips in 24-well plates. The slides were fixed with $95 \%$ alcohol for 15 minutes at room temperature. The coverslips were washed with phosphatebuffered saline (PBS) and permeabilized for 5 minutes with $0.5 \%$ Triton X-100 in PBS. The cells were then incubated with primary antibodies including anti-E-cadherin and anti-vimentin (1:100 ratios; Santa Cruz Biotechnology, Santa Cruz, USA) after blocking with 10\% normal goat or rabbit serum for $1 \mathrm{~h}$. The slides were incubated with fluorescein isothiocyanate-conjugated goat anti-mouse or antirabbit Immunoglobulin G (IgG) as the secondary antibody at room temperature for $1 \mathrm{~h}$. Slides were examined with a Nikon (Melville, USA) Eclipse TE300 fluorescence microscope, and the pictures were taken with a SPOT Diagnostic CCD camera (SPOT Imaging Solutions, Sterling Heights, USA).

The paraffin-embedded tissue blocks were sectioned for IHC analysis. In brief, tissue sections were deparaffinized and rehydrated. The endogenous peroxidase activity was blocked with $3 \%$ hydrogen peroxide for 10 minutes. For antigen retrieval, slides were immersed in $10 \mathrm{mM}$ citrate buffer ( $\mathrm{pH}$ 6.0) and boiled for 15 minutes in a microwave oven. Nonspecific binding was blocked by $5 \%$ normal goat serum for 10 minutes. The slides were incubated with 
anti-Brachyury polyclonal antibody (diluted at 1:500 ratio; Abcam, USA), anti-E-cadherin antibody, and anti-Snail polyclonal antibody (diluted at 1:200 ratio; Santa Cruz Biotechnology, Santa Cruz, USA) at $4 \mathrm{C}$ overnight in a moist chamber. The slides were sequentially incubated with biotinylated goat anti-mouse IgG (1:100 dilution; Santa Cruz Biotechnology, Santa Cruz, USA) and then with streptavidin-peroxidase conjugate, each for $30 \mathrm{mi}-$ nutes at room temperature. Isotope-matched human IgG was used in each case as a negative control. Finally, the 3, 5-diaminobenzidine Substrate Kit (Dako, Glostrup, Denmark) was used for color development followed by Mayer s hematoxylin counter staining. The slides were counterstained with hematoxylin, dehydrated and mounted. Tumor cell proportions were scored as follows: 0 (no positive tumor cells); 1 ( $<25 \%$ positive tumor cells); 2 (25 50\% positive tumor cells); and 3 ( $>50 \%$ positive tumor cells). Staining intensity was graded according to the following standard: 0 (no staining); 1 (weak staining = light yellow); 2 (moderate staining = yellow brown) and 3 (strong staining = brown). The staining index (SI) was calculated as the product of the staining intensity score and the proportion of positive tumor cells. Using this method, we evaluated nuclear Brachyury expression in HCC tumor tissues and adjacent nontumorous ones by determining the SI, with scores of $0,1,2,3,4,6,8$, 9. Only $2+$ and $3+$ was considered as a positive IHC result [20].

\section{Quantitative real-time polymerase chain reaction (qRT-PCR)}

Total RNA was isolated using Trizol reagent (Life Technologies, China), reverse transcribed with TaKaRa reverse transcription Kit (TaKaRa, Dalian, China) starting with $2 \mu \mathrm{g}$ total RNA from each sample per manufacturers instructions. The messenger ribonucleic acid (mRNA) expressions of Brachyury and housekeeping gene glyceraldehyde-3-phosphate dehydrogenase (GAPDH) were analyzed by quantitative RT-PCR using a real-time LightCycler rapid thermal cycler (Roche Molecular Biochemicals LightCycler System, Shanghai, China). Specific Brachyury primers 5-ACTGAGAATCAGCCGGA CTT-3 (forward) 5-CTGCACTGCAAAGAACCACT-3 (reverse) and internal control GAPDH primers 5-GCA CCGTCAAGGCTGAGAAC-3 (forward) and 5 -TGGTG AAGACGCCAGTGGAT-3 (reverse) were used for mRNA amplifications. For quantitative RT-PCR, $1 \mu \mathrm{l}$ of gene primers with SYBR Green (Applied Biosystems, China) in $25 \mu$ of reaction volume was used. The MTBP mRNA levels were normalized to GAPDH mRNA according to the following formula: $2^{-(\mathrm{CT} \text { target } \mathrm{CT} \text { GAPDH) }}$, where CT was the threshold cycle.

\section{Plasmids and cell transfection}

Human Brachyury was amplified by the PCR using cDNA from SMMC7721, confirmed by sequencing and subcloned into pCDNA3.1 expression vector(Invitrogen, Carlsbad, USA). Cell transfection was carried out by plating $210{ }^{5}$ HepG2 and SMMC7721 cells on six-well plate and transfected with 800-ng constructs using Lipofectamine 2000 (Invitrogen Life Technology, Carlsbad, USA) per manufacturers instructions. Briefly, cells grew $70 \%$ to 90\% confluence before transfection. The pcDNA3.1Brachyury and pcDNA3.1-control were transfected using Lipofectamine 2000 in DMEM. The cells were selected for more than 4 weeks by incubation with G418 (Invitrogen, $400 \mathrm{ng} / \mathrm{ml}$ for SMMC-7721 and $600 \mathrm{ng} / \mathrm{ml}$ for HepG2) for overexpression clones. Stable single clones were selected and Brachyury expression assessed using western blotting. Transient transfection of pcDNA3.1Brachyury and the control constructs into HCC cells were performed using Lipofectamine 2000.

\section{Protein preparation and Western blot analysis}

Harvested cells $\left(210^{6}\right)$ were placed in 1.5-ml Eppendorf tubes and homogenized with $400 \mu \mathrm{l}$ lysis buffer $(50 \mathrm{mM}$ Tris-hydrochloride, $\mathrm{pH}$ 8.0, $150 \mathrm{mM}$ sodium chloride, $0.1 \%$ sodium dodecyl sulfate, $1 \%$ Nonidet P- $40,0.5 \%$ sodium deoxycholate, $0.02 \%$ sodium azide, $100 \mu \mathrm{g} / \mathrm{ml}$ phenylmethanesulfonyl fluoride, and $1 \mu \mathrm{g} / \mathrm{ml}$ aprotinin). Cell lysates were centrifuged at $4 \mathrm{C}$ for 5 minutes at $10,000 \mathrm{rpm}$, and the protein-containing supernatant was placed in fresh tubes and quantified using the Bradford protein assay.

Western blot analysis was performed as described previously [24]. In brief, the membranes with total protein were incubated with primary antibodies: anti-Brachyury and anti-Snail (1:1000 dilutions; Cell Signaling Technology, Danvers, USA), anti-E-cadherin, anti- $\gamma$-catenin, antivimentin, anti-Akt, anti-p-Akt, and anti-PTEN (1:200 dilution; Santa Cruz Biotechnology, Santa Cruz, USA). After repeated washing, the membranes were incubated with horseradish-peroxidase-conjugated anti-rabbit or anti-mouse secondary antibody (1:2000 dilution; Santa Cruz Biotechnology, Santa Cruz, USA). The bands were visualized using the enhanced chemiluminescence detection system (Amersham Pharmacia Biotech, Piscataway, NJ, USA) and exposed to Kodak X-OMAT film (Rochester, USA). $\beta$-actin was used as an internal sample loading control. Autoradiograms were quantified using densitometry (Bio Image Intelligent Quantifier software, Bio Image Systems Inc., Jackson, MI, USA). Relative protein levels were calculated by normalization to the amount of $\beta$-actin protein.

\section{Wound healing and invasion assays}

Wound-healing assay and invasion assay were performed as described previously [12]. Cell migration was assessed by measuring the movement of cells into a scraped; a cellular area was created using a 200- $\mu$ l pipette tube, and 
the spread of wound closure was observed after 24 hours and photographed under a microscope. The \% wound healing was quantified by the space of migration tumor cells at $24 \mathrm{~h}$ after scrambled /the space of wound at $0 \mathrm{~h} 100 \%$. Cell invasion was quantified in vitro using Transwell chambers with polycarbonate membrane filters $(8-\mu \mathrm{m}$ pore size) coated with a Matrigel (Sigma, St. Louis, USA). Briefly, 48 hours after transfection, cells were washed twice using DMEM and seeded in triplicate in the inner chamber of the insert containing $200 \mu \mathrm{l}$ of serum-free medium. About $700 \mu \mathrm{l}$ of medium containing $10 \%$ fetal bovine serum was added to the lower chamber. The plates were incubated for 24 hours at $37 \mathrm{C}$. Then, the noninvading cells from the interior of the inserts were gently removed using a cotton-tipped swab. The cells that had invaded into the bottom surface of the filter were fixed with methanol and stained with hematoxylin. The invasive ability was determined by counting the penetrating cells under a microscope at 200 magnification on 10 random fields in each well. The experiments were performed in triplicate.

\section{In vivo metastasis assay}

Six-week-old male BALB/c nude mice $(\mathrm{n}=10)$ were randomized into two groups. HepG2/Brachyury or control cells $\left(210^{6}\right)$ were injected into the tail vein of nude mice. Four mice were sacrificed 6 weeks post inoculation and consecutive sections of the whole lung were subjected to hematoxylin and eosin staining. All of the metastatic foci in lung were calculated microscopically to evaluate the development of pulmonary metastasis. The remaining mice were monitored for survival analysis.

\section{Statistical analysis}

Unless otherwise indicated, data were presented as mean standard deviation of three independent experiments. SPSS statistical package for Windows (Version 12.0, SPSS Inc. Chicago, IL, USA) was used for data analysis. Based on staining intensities, the Brachyury immunoreactivity was scored as negative ( 0 to 1 ) and positive (2 to 3 ) according to a previously reported semiquantitative scoring method [25]. The clinicopathological features of Brachyury-positive and Brachyury-negative patients were compared using Pearson $x^{2}$ test for categorical variables and independent Students $\mathrm{t}$-test for continuous data. Comparisons of three or more variables were performed using one-way analysis of variance followed by Fishers protected least significant difference test. Kaplan-Meier plots and log-rank tests were used for survival analysis. The DFS times were calculated from data of curative surgery to HCC recurrence, death, or the last follow-up data. For tissue microarray analysis, based on IHC scores, Brachyury protein levels in primary $\mathrm{HCC}$ tissues and their matched metastatic tissues were compared using Wilcoxon signed-rank test. The correlation between mRNA levels of Brachyury and Snail was analyzed using Pearson $\chi^{2}$ test. A P value less than 0.05 was considered statistically significant.

\section{Results}

\section{Expression of brachyury is upregulated in human HCCs}

To explore the role of Brachyury in HCC development, the expression of Brachyury in various human $\mathrm{HCC}$ cell lines were evaluated. As shown in Figure 1A, elevated expression of Brachyury was observed in all four HCC cell lines compared with that in QZG cell lines. Brachyury mRNA was significantly increased in HCCs relative to paired noncancerous tissues of 40 patients (Figure 1B), which was further confirmed by Western blot assay (Figure 1C,D). Immunohistochemical analysis showed little positive staining of Brachyury in nontumorous liver cells, but strong nuclei staining of Brachyury (upregulated) in 62.5\% (70/112) of the patients with HCC. Brachyury was predominantly located in the nuclei of hepatocytes and tumor cells (Figure 1E). Brachyury positive expression was found in tumor tissues at a value $(62.5 \%, 70$ of 112 patients) higher than that in adjacent cirrhosis tissues (23.2\%, 26 of 112 patients) $(\mathrm{P}<0.05)$.

\section{Brachyury overexpression predicts poor prognosis of HCC} To investigate the clinical significance of Brachyury overexpression in HCC, microarray analysis of HCC tissues from 72 patients who underwent liver resection and 40 PPEP tissues was performed (Table 1). The MannWhitney $U$ test was used to assess the correlations between the staining intensity of Brachyury protein and clinicopathologic variables of HCC. As shown in Table 2, the Brachyury expression in patients with $\mathrm{HCC}$ was correlated with tumor size $(P=0.037)$, intrahepatic invasion $(\mathrm{P}=0.025)$, distance metastasis $(\mathrm{P}=0.039)$. However, the Brachyury protein staining intensity showed no significant relationship with gender, age, $\alpha$-fetoprotein and HBV infection. Based on the results from IHC, all 112 patients with HCC were divided into two groups: Brachyurypositive expression group $(\mathrm{n}=70)$ and Brachyury-negative expression group $(n=42)$. Patients in positive expression group exhibited shorter 5 -year overall survival (OS, median OS were 16 and 43 months, respectively, difference of 27 months, $\mathrm{P}=0.004$ ) than those in negative expression group (Figure 2A). Consistently, the 3-year OS rate after surgery was much lower in Brachyury-positive group than that in Brachyury-negative group (Figure 2B). Thus, Brachyury overexpression could serve as a valuable predicting factor for recurrence and poor survival of patients with HCC. 


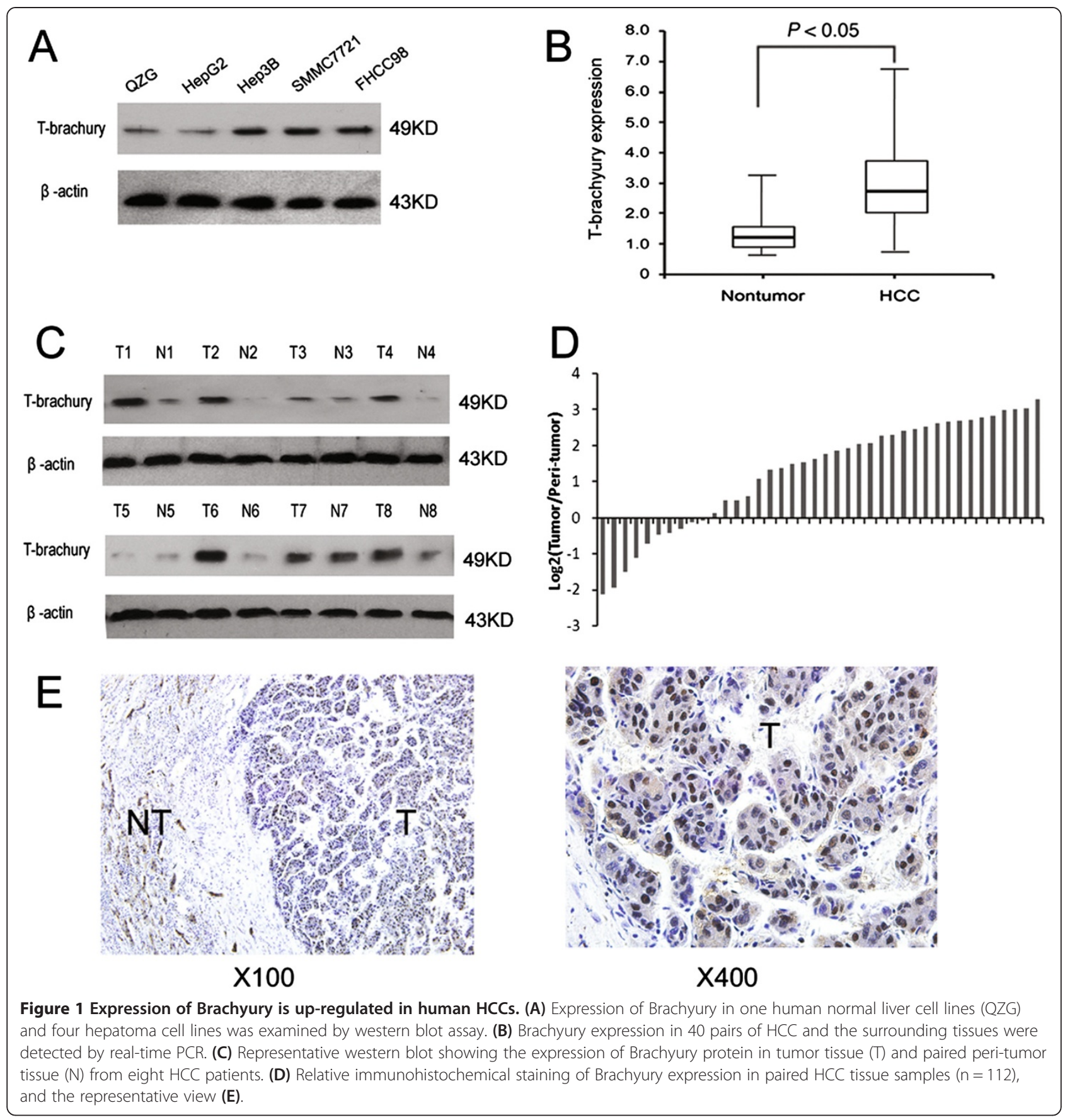

Brachyury enhances invasive and metastatic potential of HCC

The EMT promotes tumor progression by increasing the invasiveness and migratory capacity of the tumor cells. To test whether Brachyury-SMMC7721 and BrachyuryHepG2 cells acquired greater migratory and invasive capabilities, in vitro scratch wound healing and Matrigel invasion assays were performed. The Matrigel invasion assay showed that the invasiveness of the Brachyuryexpressing cells was significantly higher than empty vector-transfected cells $(\mathrm{P}<0.001$, independent Students $\mathrm{t}$ test; Figure 3A). Similarly, the wound healing assay demonstrated that the ectopic expression of Brachyury increased the cell motility in both Brachyury-SMMC7721 and Brachyury-HepG2 cells compared with VecSMMC7721 and Vec-HepG2 cells (Figure 3B). To further verify the effect of Brachyury on tumor metastasis, in vivo metastasis assay was performed in nude mice. Brachyury-HepG2 cells were injected into nude mice via tail vein, Empty vector trasfected cells were used as 
Table 1 Summary of clinicopathologic variables

\begin{tabular}{|c|c|}
\hline Characteristic & No. of patients \\
\hline Patients & 112 \\
\hline \multicolumn{2}{|l|}{ Gender } \\
\hline Male & 92 \\
\hline Female & 20 \\
\hline \multicolumn{2}{|l|}{ Age } \\
\hline$<55$ & 72 \\
\hline$\geq 55$ & 40 \\
\hline \multicolumn{2}{|l|}{ AFP $(\mu \mathrm{g} / \mathrm{L})$} \\
\hline$<100$ & 47 \\
\hline$\geq 100$ & 65 \\
\hline \multicolumn{2}{|l|}{ HBV } \\
\hline Positive & 91 \\
\hline Negative & 21 \\
\hline \multicolumn{2}{|l|}{ Liver Cirrhosis } \\
\hline Yes & 66 \\
\hline No & 46 \\
\hline \multicolumn{2}{|l|}{ Tumor size (cm) } \\
\hline$<3$ & 37 \\
\hline$\geq 3$ & 75 \\
\hline \multicolumn{2}{|c|}{ Intrahepatic metastasis } \\
\hline Y & 41 \\
\hline $\mathrm{N}$ & 71 \\
\hline \multicolumn{2}{|c|}{ Distant metastasis } \\
\hline Y & 27 \\
\hline N & 85 \\
\hline \multicolumn{2}{|l|}{ TNM stage } \\
\hline । & 27 \\
\hline$\|$ & 62 \\
\hline III & 23 \\
\hline
\end{tabular}

controls. Six weeks later, more and larger micrometastatic lesions were microscopically detected in the lungs of nude mice inoculated with Brachyury-HepG2 compared to that in the control group $(\mathrm{P}<0.001$, independent Students $\mathrm{t}$ test; Figure $3 \mathrm{C}$ ). These data suggested that Brachyury promoted HCC invasion and metastasis.

\section{Brachyury promotes EMT in HCC cells}

As EMT has been accepted as a potential mechanism underlying cancer metastasis, we explored the role of Brachyury in regulating EMT in HCC cells, Up-regulation of Brachyury in HepG2 cells resulted in the decreased expression of epithelial markers (E-cadherin and $\gamma$-catenin) and increased expression of mesenchymal marker (snail), as evidenced by immunofluorescence staining (Figure 4A). Western blot analysis also revealed that the protein level
Table 2 Relationship between Brachyury expression and clinicopathologic features of HCC patients

\begin{tabular}{|c|c|c|c|c|}
\hline \multirow[t]{2}{*}{ Features } & & \multicolumn{2}{|c|}{$\begin{array}{l}\text { Relative Brachyury } \\
\text { expression }\end{array}$} & \multirow[t]{2}{*}{ p Value } \\
\hline & & High & Low & \\
\hline \multirow[t]{2}{*}{ Sex } & Male & 60 & 32 & 0.797 \\
\hline & Female & 12 & 8 & \\
\hline \multirow[t]{2}{*}{ Age } & $<55$ & 45 & 27 & 0.683 \\
\hline & $\geq 55$ & 27 & 13 & \\
\hline \multirow[t]{2}{*}{ AFP } & $<100$ & 32 & 15 & 0.551 \\
\hline & $\geq 100$ & 40 & 25 & \\
\hline \multirow[t]{2}{*}{ HBV } & Positive & 58 & 32 & 0.807 \\
\hline & Negative & 13 & 8 & \\
\hline \multirow[t]{2}{*}{ Liver Cirrhosis } & Yes & 47 & 19 & 0.075 \\
\hline & No & 25 & 21 & \\
\hline \multirow[t]{2}{*}{ Tumor size (cm) } & $<3$ & 19 & 18 & 0.037 \\
\hline & $\geq 3$ & 53 & 22 & \\
\hline \multirow[t]{2}{*}{ Intrahepatic Metastasis } & Y & 32 & 9 & 0.025 \\
\hline & $N$ & 40 & 31 & \\
\hline \multirow[t]{2}{*}{ Distant Metastasis } & Y & 22 & 5 & 0.039 \\
\hline & $N$ & 50 & 35 & \\
\hline \multirow[t]{3}{*}{ TNM Stage } & 1 & 15 & 12 & 0.401 \\
\hline & $\|$ & 40 & 22 & \\
\hline & III & 17 & 6 & \\
\hline
\end{tabular}

of vimentin (mesenchymal marker) was increased, while E-cadherin and $\gamma$-catenin were decreased in Brachyuryoverexpressing cells compared with control cells (Figure 4B).

A similar result was observed in tissue samples of HCC. The expression of E-cadherin and vimentin in $40 \mathrm{HCC}$ samples were analyzed using Western blotting. As shown in Figure $4 \mathrm{C}$, high expression of vimentin $(\mathrm{T} / \mathrm{NT} \geq 2)$ accompanied by low expression of E-cadherin $(\mathrm{T} / \mathrm{NT}<0.5)$ was detected in HCC specimens with Brachyury overexpression ( $\mathrm{T} / \mathrm{NT} \geq 2)$. High expression of vimentin and low expression of E-cadherin was detected at 79.2\% (19/24) and $66.7 \%(16 / 24)$ in high-Brachyury expression HCC specimens $(\mathrm{T} / \mathrm{NT} \geq 2)$, respectively. Conversely, high expression of vimentin and low expression of E-cadherin was only detected at $31.3 \%(5 / 16)$ and $25.0 \%(4 / 16)$ in low-Brachyury expression HCCs (Table 3). Moreover, by linear analysis, it was found that Brachyury expression was positively correlated with vimentin $(\mathrm{p}<0.001)$ and inversely correlated with E-cadherin $(\mathrm{p}<0.01)$ (Figure 4D,E). These data further support the involvement of Brachyury in EMT as observed in HCC cells.

\section{Brachyury regulates EMT via PTEN/AKT/Snail pathway}

Numerous studies have suggested that Akt activation plays a pivotal role in tumor progression via induction of 

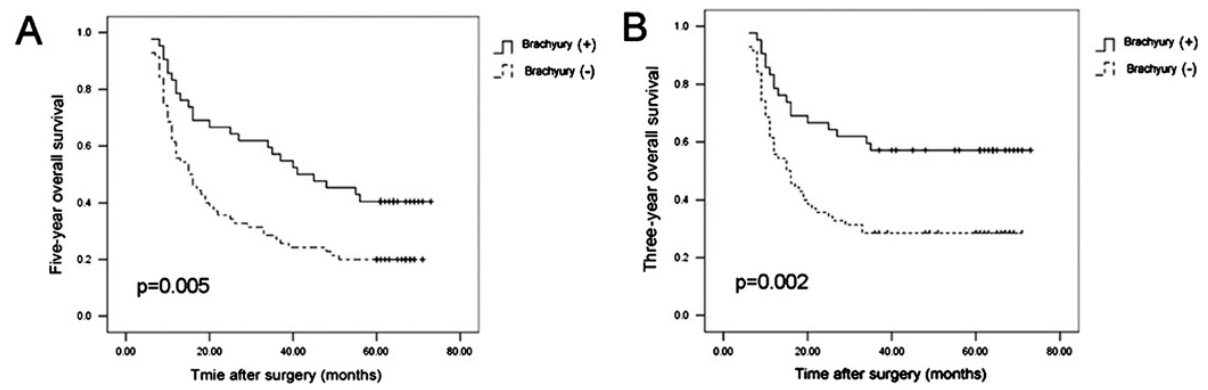

Figure 2 Brachyury overexpression predicts poor prognosis of HCC. (A) HCC patients were divided into Brachyury-positive expression group $(n=70)$ and Brachyury-negative expression group $(n=40)$. The 5-year overall of 112 HCC patients were compared between the low and high Brachyury groups. (B) The 3-year overall of $112 \mathrm{HCC}$ patients were compared between the low and high Brachyury groups.

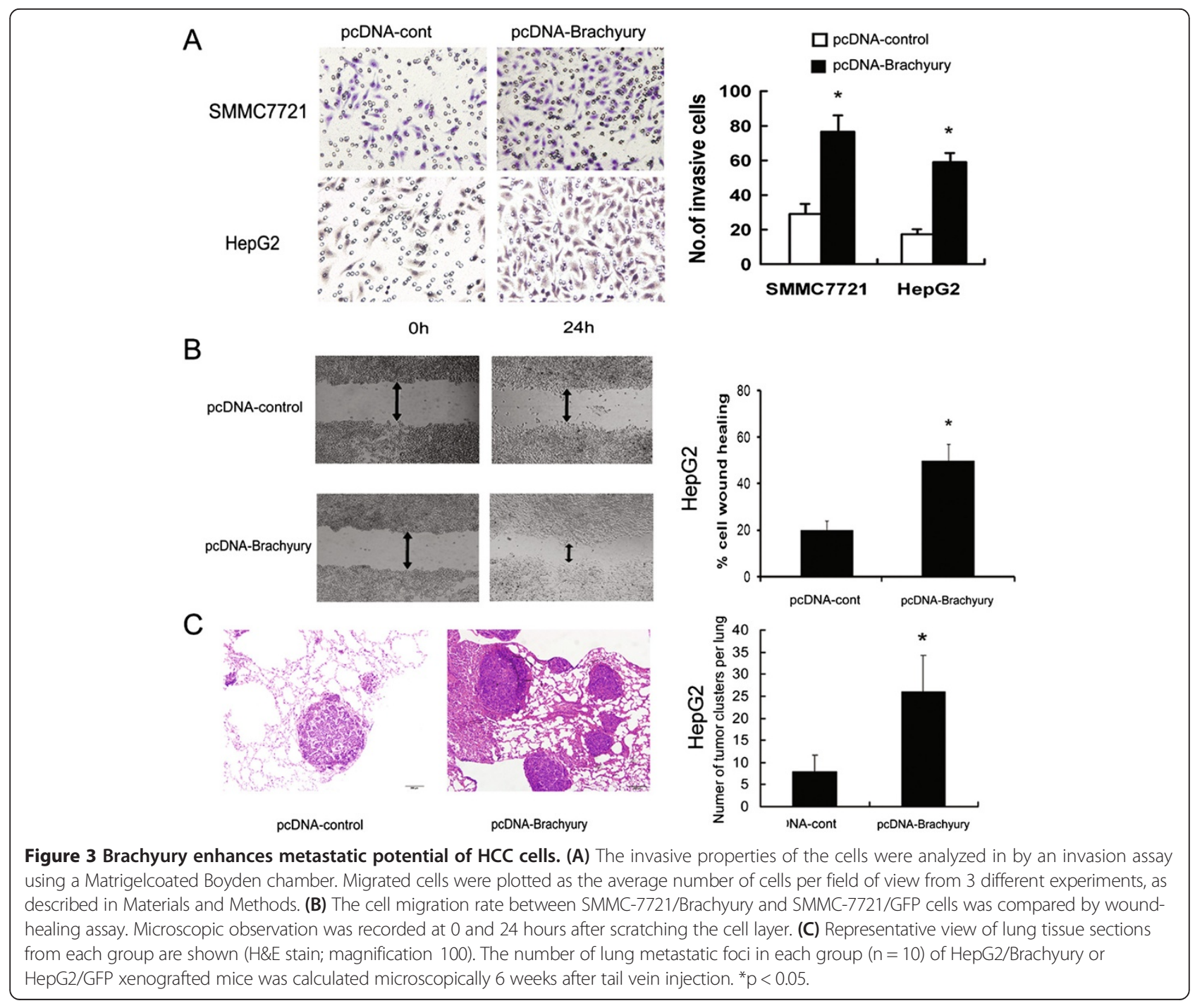




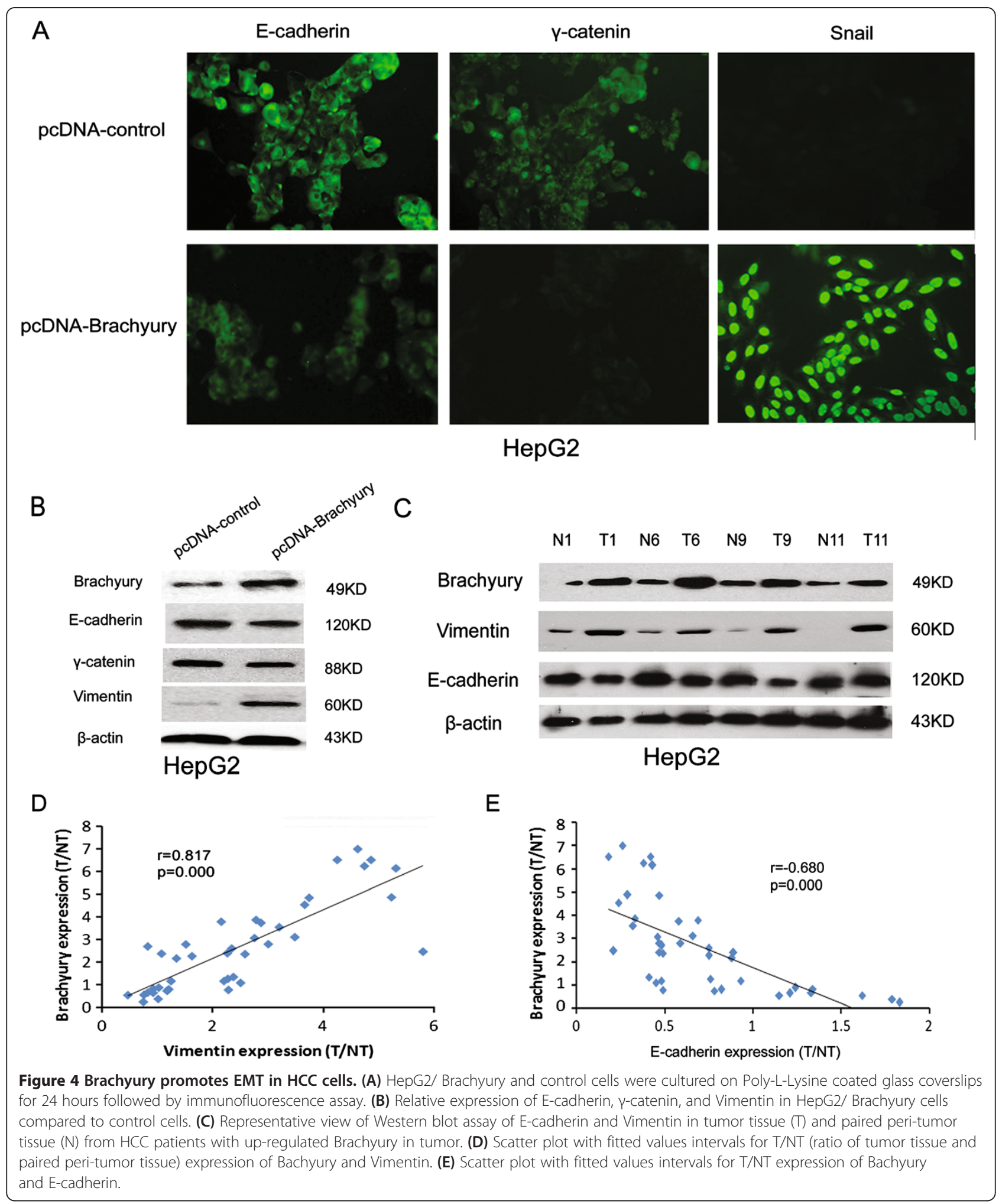

EMT [26-29]. Thus, the Akt activation is usually up- and downregulated by tumor suppressor PTEN. Western blot revealed that PTEN expression was significantly influenced by Brachyury overexpression (Figure 5A), and it confirmed the involvement of PTEN in Brachyurymediated Akt activation. Snail has been documented to be regulated by Akt and is a predominant mediator of EMT [30,31]. To test if Snail was involved in Brachyury- 
Table 3 Relationship between Brachyury expression and vimentin/E-cadherin in 40 HCC tissues

\begin{tabular}{|c|c|c|c|c|c|}
\hline & & \multicolumn{2}{|c|}{ Vimentin T/NT } & \multicolumn{2}{|c|}{ E-cadherin T/NT } \\
\hline & & $\geq 2$ & $<2$ & $>0.5$ & $\leq 0.5$ \\
\hline \multirow[t]{2}{*}{ Brachyury T/NT } & $\geq 2$ & 19 & 5 & 8 & 16 \\
\hline & $<2$ & 5 & 11 & 12 & 4 \\
\hline$p$-Value & & & 0.001 & & 0.01 \\
\hline
\end{tabular}

mediated EMT, the effect of Brachyury on Snail activation was examined. As expected, expression of Snail was significantly increased in cells with Brachyuryoverexpression.

The Akt/Snail pathway involvement in EMT-mediated Brachyury-overexpressed HCC cells was investigated. Brachyury-HepG2 cells were treated with Akt inhibitor (LY290004) and small interfering RNA (siRNA) against Snail, and the effects on cell EMT were determined as described previously. As shown in Figure 5, treatment with Akt inhibitor prevented the Brachyury-mediated increase in p-Akt and Snail (Figure 5B). Transfection with siRNA against Snail effectively abolished Brachyuryinduced Snail expression (Figure 5C). The expression of E-cadherin was correspondingly increased while vimentin was reduced in Brachyury-transfected cells after treatment with Akt inhibitor or Snail siRNA. These results indicate that Brachyury mediates the mesenchymal transition of HCC cells through the Akt/Snail pathway.

\section{Discussion}

Recently, accumulating evidence has suggested that TBrachyury plays an important role in carcinogenesis and metastasis of multiple types of human cancers, and may serve as a prognosis marker. Nerbil et al. found that early stages colorectal cancer patients (T1-2N0M0, Dukes A) showed a significantly decreased survival when Brachyury was expressed in the tumour tissue while no correlation was observed in later tumour stages, suggesting a possibility to detect metastatic cancers during early stages of colorectal carcinogenesis by using an antibody against brachyury in immunohistochemistry analysis [18]. Brachyury was shown to be overexpressed in human lung tumors [32]. Furthermore, Brachyury mRNA expression in primary lung carcinoma tissues was demonstrated as a significant predictor of poor prognosis for 5 -year disease-free survival and overall survival rates and was significantly correlated to vascular invasion, lymphatic permeation, histological grade, pathologic $\mathrm{T}$ stage,

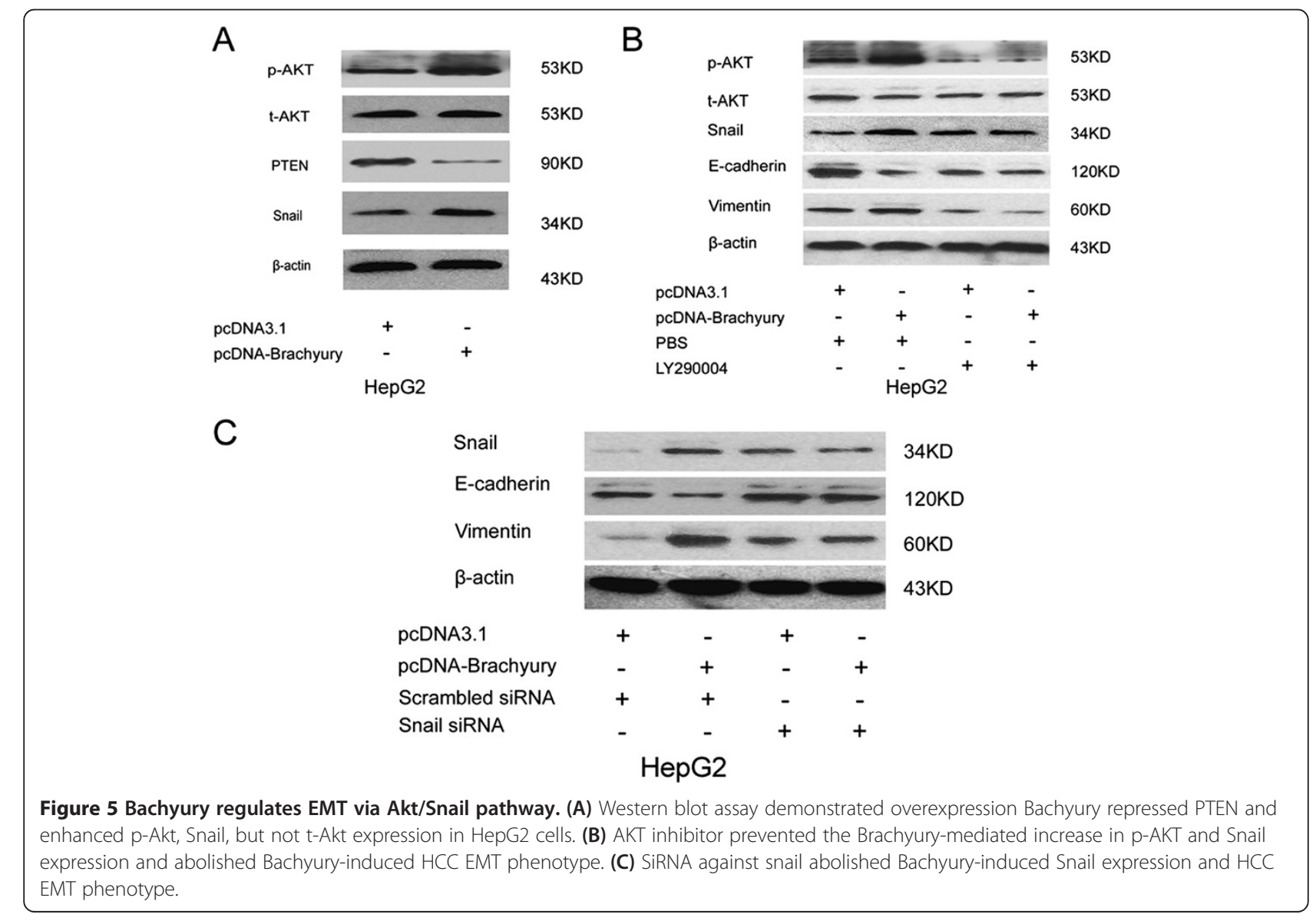

B 
and pathologic $\mathrm{N}$ stage [33]. In addition, Palena and colleagues also revealed that overexpression of brachyury in breast carcinomas is associated with poor prognosis [34]. More recently, Brachyury was shown to be overexpressed in prostate cancer and metastatic tumors when compared with normal tissues and play an important role in prostate cancer aggressiveness [35]. Here, we presented for the first time that the Brachyury was highly expressed in HCC tissues compared with adjacent nontumorous tissues; Brachyury expression was correlated with tumor size $(\mathrm{P}=0.037)$, intrahepatic invasion $(\mathrm{P}=$ $0.025)$, distance metastasis $(P=0.039)$, and outcome of HCCs, adding to the evidence that Brachyury may serve as a prognosis marker and potential therapeutic target for HCC.

The EMT usually occurs in the critical phases of embryonic development and organ fibrosis. This program has also been shown to be the pivotal mechanism contributing to cancer metastasis [36]. It is well established that EMT gives rise to the dissemination of single carcinoma cell from the site of the primary tumor [37]. The EMT has also been reported to be involved in the progression of $\mathrm{HCC}$ and correlates with the prognosis of cancer metastasis [12]. Recently, Brachyury has been identified as an important EMT regulator by modulating Slug and E-cadherin expression in various tumor cells; however, whether Brachyury promotes hepatoma cells EMT and cancer metastasis is not clear so far. The study data suggest that Brachyury promotes hepatoma cells metastasis through modulation of its EMT phenotype. This notion was based on the findings as follows: (1) Mesenchymal markers were significantly upregulated in the Brachyury overexpression HCC cell lines, whereas the epithelial markers were remarkably decreased by immunocytochemical analysis. (2) These results were further confirmed by immunostaining analysis of cultured cells and HCC tissues. (3) In vitro and in vivo metastasis assays demonstrated that enforced Brachyury enhanced the metastasis potential of $\mathrm{HCC}$ cells and induced more metastatic lesions in liver of nude mice. Therefore, these experimental data indicated that Brachyury might promote HCC metastasis through, at least partially, induction of EMT in hepatoma cells.

Brachyury was recently demonstrated to induce EMT in human epithelial cells through repression of Ecadherin and induction Slug [20]. Another study demonstrates that Brachyury expression is enhanced during TGF- $\beta 1$-induced EMT in various human cancer cell lines, and a positive feedback loop is established between Brachyury and TGF- $\beta 1$ in mesenchymal-like tumor cells. Interestingly, Brachyury overexpression could promote TGF- $\beta 1$ upregulation by activating its promoter, while inhibition of its signaling could decrease Brachyury expression, induce a mesenchymal-to-epithelial transition, and provide increased susceptibility to tumor cells towards chemotherapy [38]. The present study focused on the regulation of AKT pathway, because increasing evidence had demonstrated that activated AKT pathway could play a central role in EMT process and tumor metastasis [26-29]. Activation of Akt in Brachyury-induced EMT was observed in the study, correlating with vimentin induction and E-cadherin downregulation. Further, Snail has been documented to be regulated by Akt, and it has been a predominant mediator of EMT [30,31]. The experimental data of present study showed that expression of Snail was significantly increased in cells with Brachyury overexpression. Additionally, treatment with Akt inhibitor prevented the Brachyury-mediated increase in p-Akt and Snail, and transfection with siRNA against Snail effectively abolished Brachyury-induced Snail expression. These experimental data provide evidence that Brachyury could promote EMT of hepatoma cells via Akt/Snail-dependent pathway. It was hypothesized that Brachyury might activate cytoplasmic Akt signal pathway to repress the tumor suppressor PTEN. Overexpression of PTEN has been reported to strongly inhibit the EMT of mesoderm cells. The functions of PTEN as a negative regulator of the PI3K/Akt pathway via dephosphorylation of PtdIns $(3,4,5) \mathrm{P}(3)$ has been reported, participating in regulation of EMT during cancer progression [39]. The study data demonstrated that PTEN expression was significantly influenced by Brachyury overexpression. However, more evidence is required to confirm whether PTEN expression is directly regulated by Brachyury.

To summarize, Brachyury could play an important role in HCC metastasis by EMT induction via, at least partially, PTEN/AKT/Snail-dependent pathway; and it may serve as a valuable prognostic biomarker and potential therapeutic target. The present study results uncovered a novel function and molecular mechanism for Brachyury in HCC which will shed new light on the understanding of tumor progression and metastasis.

\section{Competing interests}

The authors declare that they have no competing interests.

\section{Authors contributions}

RD, SSW and XNL made substantial contributions to conception and design as well as carried out all the experiments reported here. HHF, SDW, JZh, JYW and XHZh collected clinical data and analyzed the data. JBK conceived the study and participated in its design and coordination. All authors read and approved the final manuscript.

\section{Acknowledgements}

The present work was supported by grants from National Natural Science Foundation of China (Grant no. 81300789).

\section{Author details}

${ }^{1}$ Department of Radiation Oncology and Integrative Oncology, Navy General Hospital, 6\# Fu Cheng Road, Beijing 100037, Peoples Republic of China. ${ }^{2}$ Department of Aviation and Diving, Navy General Hospital, Beijing, Peoples Republic of China. 
Received: 12 August 2014 Accepted: 24 November 2014

Published online: 14 December 2014

\section{References}

1. Farazi PA, DePinho RA: Hepatocellular carcinoma pathogenesis: from genes to environment. Nat Rev Cancer 2006, 6:674 687.

2. Mathurin P, Rixe O, Carbonell N, Bernard B, Cluzel P, Bellin MF, Khayat D, Opolon P, Poynard T: Review article: overview of medical treatments in unresectable hepatocellular carcinoma-an impossible meta-analysis? Aliment Pharmacol Ther 1998, 12:111 126.

3. Kawano Y, Sasaki A, Kai S, Endo Y, Iwaki K, Uchida H, Shibata K, Ohta M, Kitano S: Prognosis of patients with intrahepatic recurrence after hepatic resection for hepatocellular carcinoma: a retrospective study. European J Surg Oncol J Eur Soc Surg Oncol Br Assoc Surg Oncol 2009, 35:174 179.

4. Liotta LA: Mechanisms of cancer invasion and metastasis. Important advances in oncology 1985:28 41.

5. Thiery JP, Acloque H, Huang RY, Nieto MA: Epithelial-mesenchymal transitions in development and disease. Cell 2009, 139:871 890.

6. Larue L, Bellacosa A: Epithelial-mesenchymal transition in development and cancer: role of phosphatidylinositol 3' kinase/AKT pathways. Oncogene 2005, 24:7443 7454.

7. Christofori G: New signals from the invasive front. Nature 2006, 441:444 450

8. Boivin D, Bilodeau D, Beliveau R: Regulation of cytoskeletal functions by Rho small GTP-binding proteins in normal and cancer cells. Can J Physiol Pharmacol 1996, 74:801 810.

9. Niu RF, Zhang $L, X i$ GM, Wei XY, Yang Y, Shi YR, Hao XS: Up-regulation of Twist induces angiogenesis and correlates with metastasis in hepatocellular carcinoma. J Exp Clin Cancer Res CR 2007, 26:385 394.

10. Teng Y, Zeisberg M, Kalluri R: Transcriptional regulation of epithelialmesenchymal transition. J Clin Invest 2007, 117:304 306.

11. Naiche LA, Harrelson Z, Kelly RG, Papaioannou VE: T-box genes in vertebrate development. Annu Rev Genet 2005, 39:219 239.

12. Zhou B, Chen H, Wei D, Kuang Y, Zhao X, Li G, Xie J, Chen P: A novel miR-219-SMC4-JAK2/Stat3 regulatory pathway in human hepatocellular carcinoma. J Exp Clin Cancer Res 2014, 33:55.

13. Beddington RS, Rashbass $P$, Wilson V: Brachyury-a gene affecting mouse gastrulation and early organogenesis. Dev Supp/ 1992, 157-165.

14. Schulte-Merker S, van Eeden FJ, Halpern ME, Kimmel CB, Nusslein-Volhard C: no tail ( $\mathrm{ntl}$ ) is the zebrafish homologue of the mouse T (Brachyury) gene. Development 1994, 120:1009 1015.

15. Wilson V, Manson L, Skarnes WC, Beddington RS: The T gene is necessary for normal mesodermal morphogenetic cell movements during gastrulation. Development 1995, 121:877 886.

16. Showell C, Binder O, Conlon FL: T-box genes in early embryogenesis. Dev Dyn Off Publ Am Assoc Anat 2004, 229:201 218.

17. Griffin KJP, Kimelman D: One-Eyed Pinhead and Spadetail are essential for heart and somite formation. Nat Cell Biol 2002, 4:821 825.

18. Kilic N, Feldhaus S, Kilic E, Tennstedt P, Wicklein D, Wasielewski R, Viebahn C, Kreipe $\mathrm{H}$, Schumacher U: Brachyury expression predicts poor prognosis at early stages of colorectal cancer. Eur J Cancer 2011, 47:1080 1085.

19. Yang XR, Ng D, Alcorta DA, Liebsch NJ, Sheridan E, Li S, Goldstein AM, Parry DM, Kelley MJ: T (Brachyury) gene duplication confers major susceptibility to familial chordoma. Nat Genet 2009, 41:1176 1178.

20. Fernando RI, Litzinger M, Trono P, Hamilton DH, Schlom J, Palena C: The T-box transcription factor Brachyury promotes epithelial-mesenchymal transition in human tumor cells. J Clin Invest 2010, 120:533 544.

21. Huang B, Cohen JR, Fernando RI, Hamilton DH, Litzinger MT, Hodge JW, Palena C: The embryonic transcription factor Brachyury blocks cell cycle progression and mediates tumor resistance to conventional antitumor therapies. Cell Death Dis 2013, 4:e682.

22. Imajyo I, Sugiura T, Kobayashi Y, Shimoda M, Ishii K, Akimoto N, Yoshihama N, Kobayashi I, Mori Y: T-box transcription factor Brachyury expression is correlated with epithelial-mesenchymal transition and lymph node metastasis in oral squamous cell carcinoma. Int J Oncol 2012, 41:1985 1995.

23. Wong N, Lai P, Lee SW, Fan S, Pang E, Liew CT, Sheng Z, Lau JW, Johnson PJ: Assessment of genetic changes in hepatocellular carcinoma by comparative genomic hybridization analysis: relationship to disease stage, tumor size, and cirrhosis. Am J Pathol 1999, 154:37 43.

24. Weiss-Steider B, Soto-Cruz I, Martinez-Campos CA, Mendoza-Rincon JF: Expression of MICA, MICB and NKG2D in human leukemic myelomonocytic and cervical cancer cells. J Exp Clin Cancer Res 2011, 30:37.
25. Chen L, Chan TH, Yuan YF, Hu L, Huang J, Ma S, Wang J, Dong SS, Tang KH, Xie D, Li Y, Guan XY: CHD1L promotes hepatocellular carcinoma progression and metastasis in mice and is associated with these processes in human patients. CHD1L promotes hepatocellular carcinoma progression and metastasis in mice and is associated with these processes in human patients. J Clin Invest 2010, 120:1178 1191.

26. Thiery JP, Sleeman JP: Complex networks orchestrate epithelial-mesenchymal transitions. Nat Rev Mol Cell Biol 2006, 7:131 142

27. Ning J, Liu W, Zhang J, Lang Y, Xu S: Ran GTPase Induces EMT and Enhances Invasion in Non-Small Cell Lung Cancer Cells Through Activation of PI3K-AKT Pathway. Oncol Res Featuring Preclin Clin Cancer Ther 2014, 21:67 72.

28. Ginnebaugh KR, Ahmad A, Sarkar FH: The therapeutic potential of targeting the epithelial-mesenchymal transition in cancer. Expert Opin Ther Targets 2014, 18:731 745.

29. Tian H, Ge C, Li H, Zhao F, Hou H, Chen T, Jiang G, Xie H, Cui Y, Yao M, Li J: Ribonucleotide reductase $\mathrm{M} 2 \mathrm{~B}$ inhibits cell migration and spreading by early growth response protein 1-mediated phosphatase and tensin homolog/Akt1 pathway in hepatocellular carcinoma. Hepatology 2014, 59:1459 1470

30. Chen KC, Chen CY, Lin CJ, Yang TY, Chen TH, Wu LC, Wu CC: Luteolin attenuates TGF-beta1-induced epithelial-mesenchymal transition of lung cancer cells by interfering in the PI3K/Akt-NF-kappaB-Snail pathway. Life Sci 2013, 93:924 933.

31. Yang MH, Chen CL, Chau GY, Chiou SH, Su CW, Chou TY, Peng WL, Wu JC: Comprehensive analysis of the independent effect of twist and snail in promoting metastasis of hepatocellular carcinoma. Hepatology 2009, 50:1464 1474.

32. Roselli M, Fernando Rl, Guadagni F, Spila A, Alessandroni J, Palmirotta R, Costarelli L, Litzinger M, Hamilton D, Huang B, Tucker J, Tsang KY, Schlom J, Palena C: Brachyury, a driver of the epithelial-mesenchymal transition, is overexpressed in human lung tumors: an opportunity for novel interventions against lung cancer. Clin Cancer Res 2012, 18:3868 3879.

33. Haro A, Yano T, Kohno M, Yoshida T, Koga T, Okamoto T, Takenoyama M, Maehara Y: Expression of Brachyury gene is a significant prognostic factor for primary lung carcinoma. Ann Surg Oncol 2013, 20(Suppl 3):S509 S516.

34. Palena C, Roselli M, Litzinger MT, Ferroni P, Costarelli L, Spila A, Cavaliere F, Huang B, Fernando Rl, Hamilton DH, Jochems C, Tsang KY, Cheng Q, Kim Lyerly H, Schlom J, Guadagni F: Overexpression of the EMT driver brachyury in breast carcinomas: association with poor prognosis. J Nat/ Cancer Inst 2014, 9:106(5)

35. Pinto F, Prtega-Gomes N, Pereira MS, Vizcano JR, Monteiro P, Henrique RM, Baltazar F, Andrade RP, Reis RM: T-box transcription factor brachyury is associated with prostate cancer progression and aggressiveness. Clin Cancer Res 2014, 20:4949 4961.

36. Lim J, Thiery JP: Epithelial-mesenchymal transitions: insights from development. Development 2012, 139:3471 3486.

37. Thiery JP: Epithelial-mesenchymal transitions in tumour progression. Nat Rev Cancer 2002, 2:442 454

38. Larocca C, Cohen JR, Fernando RI, Huang B, Hamilton DH, Palena C: An Autocrine Loop between TGF- $\beta 1$ and the Transcription Factor Brachyury Controls the Transition of Human Carcinoma Cells into a Mesenchymal Phenotype. Mol Cancer Ther 2013, 12:1805 1815.

39. Leslie NR, Yang $X$, Downes CP, Weijer CJ: Ptdlns(3,4,5)P3-Dependent and -Independent Roles for PTEN in the Control of Cell Migration. Curr Biol 2007, 17:115 125.

doi:10.1186/s13046-014-0105-6

Cite this article as: Du et al:: Overexpression of brachyury contributes to tumor metastasis by inducing epithelial-mesenchymal transition in hepatocellular carcinoma. Journal of Experimental \& Clinical Cancer Research 2014 33:105. 